\title{
Exploration on the Reform of Practice Teaching System of Applied Undergraduate "Data Structure and Algorithm" Based on Outcome-Based Education
}

\author{
Heng $\mathrm{Li}^{1}{ }^{1, *}$ Juan Peng ${ }^{1}$ Ya-hong Leng ${ }^{1}$ Hong-shi Zhang ${ }^{1}$ \\ ${ }^{1}$ College of Software, Chongqing Institute of Engineering, Chongqing 400056, China \\ ${ }^{*}$ Corresponding author. Email: ylgllh@126.com
}

\begin{abstract}
The outcome-based education (OBE) philosophy emphasizes "student-oriented, result-oriented, continuous improvement". Based on the practical teaching practice of the core course "Data Structure and Algorithm" for engineering majors of application undergraduate, it is proposed that the OBE education concept should be integrated into the practical teaching system reform of "Data Structure and Algorithm". The reform ways of the preparatory process of practical teaching are analyzed from four aspects: talent training plan, practical teaching syllabus, practical teaching faculty, and practical teaching textbooks. The reform strategies of "four characteristics" in the implementation of practical teaching focus on: building "open" laboratory, strengthening "comprehensive and designed" experiment, and promoting "innovation" by competition. The reform measures of practice teaching assessment are explored from two perspectives: practice teaching assessment mode, and assessment result analysis. The purpose is to strengthen the training of students' basic skills, application abilities and comprehensive qualities, so as to achieve a seamless connection between the quality of talent training and the needs of engineering applications. The reform of the practical teaching system of similar courses in related institutes can be used for reference.
\end{abstract}

Keywords: OBE, Applied undergraduate, Data Structure and Algorithm, Practice teaching system, Reform.

\section{INTRODUCTION}

OBE (Outcome-Based Education) is an educational philosophy of "student-oriented, resultoriented, and continuous improvement". It emphasizes that what students learn and what results they obtain are far more important than when and how to learn. It is required that all teaching activities (teaching preparation, teaching implementation, teaching assessment, etc.) should focus on the knowledge, ability and quality acquired by the students. Learning effectiveness drives the operation of the teaching system. It is an innovation of the traditional education model.

"Data Structure and Algorithm" is a

*Fund: This paper is supported by the following teaching and research platforms: New secondary college of general undergraduate institute in Chongqing - Chongqing institute of engineering (college of software and artificial intelligence), December, 2018 . professional core course for applied undergraduate related engineering majors. It is an important foundation and strong support for learning software development and design professional courses. This course has the characteristics of deep theory, strong abstraction, high requirements for computational thinking, many practical applications, and difficult learning. As of 2020, more than 1,300 majors in more than 200 Institutes in China have passed the engineering education certification based on the OBE education philosophy. However, applying the relevant engineering majors of undergraduate institutes to integrate the OBE concept into the practical teaching system, some are just getting started, some are still less than one training cycle, and some are not comprehensive and in-depth. Therefore, relevant engineering majors of applied undergraduate institutes must make every effort to break through the fetters of traditional teaching concepts, models and methods, vigorously promote 
the integration of $\mathrm{OBE}$ educational ideas and methods into the practical teaching system of professional core courses, carry out the whole process and all-element reforms of the training program, syllabus, teaching implementation and teaching evaluation of the "Data Structure and Algorithm" practical course, and strive to achieve three changes: from subject-oriented to goaloriented, from teacher-centered to student-centered, and from quality monitoring to continuous improvement [1].

\section{PRACTICAL TEACHING PREPARATION REFORM BASED ON OBE}

Practice teaching preparation is the first link of practice teaching system, and it is the basis and premise of all-round reform of "Data Structure and Algorithm" practice teaching system based on OBE concept.

\section{1 "Three Relations" Should Be Clarified in Talent Training Program}

"Three relationships" should be clarified in the talent training program of Engineering Specialty in applied undergraduate course.

- The relationship between theory and practice teaching of "Data Structure and Algorithm".

If the total class hour is 64 , the class hour allocation is usually: 40 class hours of theory +24 class hours of practice ( 8 class hours of experiment +16 class hours of curriculum design).

- The leading and following relationship between "Data Structure and Algorithm" practice course and other courses.

The leading courses of "Data Structure and Algorithm" for application undergraduate mainly include: introduction to software engineering, $\mathrm{C}$ language programming, $\mathrm{C}$ language programming experiment, and the following courses mainly include: database technology and application, object-oriented programming, software engineering, etc. This leading and following relationship is reflected through the logical link diagram of curriculum and teaching links.

- The supporting relationship between the practical course of "Data Structure and Algorithm" and graduation requirements.
Based on the OBE education concept, the supporting relationship between the practical teaching of "Data Structure and Algorithm" and the graduation requirements is mainly reflected in the ability to complete the design and implementation of the system, algorithm, module, etc., as well as the optimization and improvement of the software process, with a sense of innovation.

\section{2 "Three Goals" Should Be Highlighted in Practice Teaching Syllabus}

In the practical teaching syllabus of "Data Structure and Algorithm" for application undergraduate, the role and status of the course, the characteristics of the course, the relationship with other courses, and the "three major objectives" (knowledge, skills and literacy) obtained by students should be clarified.

- Knowledge goal: T1. Mastering the typical algorithm and its practical application in the industry.

- Capability Objective: T2. Having the ability to select reasonable data structure and development platform for algorithm design. T3. Having the ability to use the theory and tools of "Data Structure and Algorithm" to solve practical problems.

- Literacy goal: T4. Developing the habit of comprehensive analysis and comprehensive consideration, and shaping the spirit of unity, cooperation and tenacity.

\section{3 "Three Combinations" of Practical Teaching Teachers Should Be Realized}

The teaching staff of practical teaching of "Data Structure and Algorithm" for application undergraduate course is usually composed of 5 persons (depending on the number of students, each teacher generally teaches 2-3 administrative classes, and each administrative class generally has about 50 persons), including at least one senior professional title teacher and two teachers who have been in the course for more than 2 years, so as to realize the "Three Combinations" of the old, the middle-aged and the young. 


\section{4 "Three Strengthening" Should Be Embodied in Practical Teaching Materials}

At present, there are a large number of practical teaching materials of "Data Structure and Algorithm" in the market, but the pertinence and practicability are not very good, which cannot fully meet the requirements of application undergraduate institutes. Therefore, the relevant application undergraduate institutes should jointly compile the practical teaching material of "Data Structure and Algorithm", and strive to embody the "three strengthening" of the practical teaching material: first, strengthen the practical teaching, and the experiment + curriculum design should occupy 24 class hours; second, strengthen the applicationoriented characteristics, and highlight the practicability, comprehensiveness and design in the content selection according to the characteristics of the students in the application undergraduate institutes; third, strengthen the application-oriented characteristics. It is to strengthen instituteenterprise cooperation, and actively cooperate with enterprises and industries to compile practical teaching materials.

\section{PRACTICE TEACHING IMPLEMENTATION REFORM ON OBE}

The implementation of practice teaching is the middle link of the course practice teaching system. It is the core content and main embodiment of the comprehensive reform of the practice teaching system of "Data Structure and Algorithm" based on the OBE education concept. "Four characteristics" practice teaching based on OBE (openness, comprehensiveness, design and innovation) must be carried out vigorously. The main goal is to solve the problem that students have the ability of single experiment verification and lack the ability of comprehensive design and practical application.

\subsection{Building "Open" Laboratory}

The course system of "Data Structure and Algorithm" should be optimized, and the course of "Data Structure and Algorithm experiment" should be set up separately. The experimental hours should account for $1 / 3$ to $1 / 2$ of the total hours, at least 24 hours. It is necessary to establish a "Data Structure and Algorithm" laboratory which is shared by the whole Institute and open to the whole working hours. The laboratory area and the number of experimental equipment should meet the standards and requirements of engineering education certification based on OBE, and build the relevant operating environment, question bank environment and evaluation environment.

\subsection{Strengthening "Comprehensive and Design" Experiment Content}

The proportion of designed and comprehensive experiments in "Data Structure and Algorithm" experiment is increased, with at least 16 class hours. It can be organized and implemented in the following three ways:

The enterprise case base of "Data Structure and Algorithm" experiment is established. According to the characteristics of "Data Structure and Algorithm" experiment course, enterprise cases are decomposed to form the corresponding case base of "Data Structure and Algorithm" experiment, and cases are integrated into experimental projects, especially comprehensive and design experimental projects.

Over the years, comprehensive and designed experimental projects developed by all teachers are integrated. According to the requirements and standards of OBE, the comprehensive and designed experimental projects developed by all teachers over the years are adjusted and optimized. Those that do not meet the OBE requirements and standards will be deleted when they need to be deleted, and those that need to be modified will be modified.

ICPC (International Collegiate Programming Contest) question bank is used. The competition topics of ICPC are carefully selected to form a set of experimental questions at three levels: junior, middle and senior. The primary questions are confirmatory, the intermediate questions are designed and comprehensive, and the advanced questions are complex and designed and comprehensive. According to the learning progress and the specific requirements of the teacher, students select the corresponding level of experimental problems, especially the design and comprehensive experimental problems. Changing the traditional practice teaching system for algorithm based experimental problems into the practice teaching system for solving practical problems with appropriate algorithms will help to improve the students' ability to solve "complex engineering problems" and achieve the goal to the 
requirements of engineering education certification based on OBE concept [5].

\subsection{Promoting "Innovation" by Competition}

Students must be encouraged and supported to take part in professional competitions and scientific and technological innovation activities such as "Blue Bridge Cup Software Design Competition", "China University Computer Design Competition" and "International University Program Design Competition", so as to achieve the purpose of promoting learning by competition The specific measures are as follows: set up different professional competition studios, select experienced teachers as instructors, invite senior students with successful experience to give regular guidance, introduce corresponding incentive mechanism, ensure the smooth development of professional competition, and improve students' practical ability and innovation ability in an all-round way.

\section{PRACTICE TEACHING ASSESSMENT REFORM BASED ON OBE}

Practical teaching assessment is the end of the practical teaching system, which is the touchstone and feedback device of the comprehensive reform of the practical teaching system of "Data Structure and Algorithm" based on OBE.

\subsection{Practice Teaching Assessment Mode}

The practice assessment of "Data Structure and Algorithm" adopts a combination of formative assessment (80-70\%) and project defense (20$30 \%)$.

\subsubsection{Formative Assessment (80-70\%)}

\subsubsection{Daily Attendance (10\%)}

3 points / time will be deducted for asking for leave due to illness, 5 points / time will be deducted for being late or leaving early ( $\leqslant 20$ minutes), 10 points / time will be deducted for being absent for more than 20 minutes, and those who have been absent for more than one third of the total course hours will be disqualified and can only take another course. Change number of columns: Select the Columns icon from the MS Word Standard toolbar and then select "1 Column" from the selection palette.

\subsubsection{Source Code (30\%)}

Students submit the source code corresponding to the experimental content, and use the online judge system to automatically compile and run in real time, and give the evaluation results. This evaluation method is not limited by space and time, can be carried out at any time and get the results in real time, which not only facilitates the students' experiment, but also improves the monitoring of the learning process, and greatly reduces the workload of teachers [6].

\subsubsection{Experimental Reports (40-30\%)}

It is the most direct embodiment of students' comprehensive summary of experimental content, mainly including the name of experimental project, experimental purpose, experimental principle, experimental requirements, experimental platform or tools, experimental process, experimental results and so on. The teacher must carefully review each student's experimental report, and give a score according to the source code operation, so as to avoid students copying each other.

\subsubsection{Project Oral Defense (20-30\%)}

The project defense is divided into groups (usually 3-5 people in a group), the time is about 20 minutes, each group of 1-2 students on stage to report the project design content in the form of PPT, the time is about 8 minutes, the main report content is: design requirements, basic content, main methods, task completion, results and characteristics, experience and improvement thinking, etc., after the presentation, the project function needs to be demonstrated, the time is 7 minutes. The judge teacher asked 2-3 questions to the students, and the respondent answered the questions for about 5 minutes. The questions focused on the basic theory, basic skills and application ability of the course, so as to identify the ability of students to work independently, analyze and solve problems.

\subsection{Analysis and Feedback of Assessment Results}

\subsubsection{Results Statistical Analysis}

The main contents of statistical analysis are: the highest score, the lowest score, the average score, the number and ratio of statistics in each section, 
whether it conforms to the normal distribution, standard deviation, etc.

\subsubsection{Quality Feedback}

Comprehensive score statistics and analysis, institute and college leaders' lectures, institute and college supervision experts' lectures, institute and college classroom order inspection, students' evaluation of teaching, etc., systematically analyze the achievement of OBE teaching objectives and the corresponding causes, and comprehensively review the existing problems and improvement measures.

\section{CONCLUSION}

The reform of curriculum practice teaching system based on OBE education concept is a gradual process of continuous exploration, practice, summary, improvement and promotion. Especially for the engineering majors in applied undergraduate institutes, it is more necessary to actively change the concept, continuously implement the reform and constantly summarize and improve. This paper only discusses the whole process and all elements reform strategy of the practical teaching system of "Data Structure and Algorithm" course, which has the value of popularization and application, and can be used for reference in the reform of practical teaching system of related professional courses in similar institutes. In the next step, we will continue to improve and perfect some reform contents to ensure that the training personnel meet the requirements and standards of engineering education certification based on OBE.

\section{AUTHORS' CONTRIBUTIONS}

Heng Li conceived the architecture and wrote the main content, Juan Peng wrote the manuscript, Ya-hong Leng wrote the manuscript, Hong-shi Zhang contributed to revising and editing.

\section{REFERENCES}

[1] Li Zhiyi, Zhu Hong, Liu Zhijun, Xia Yuan Jing. Guided by the results oriented educational philosophy, the reform of higher engineering education is guided by [J]. Higher engineering education research, 2014 (02): 29$34+70$.

[2] Wang Feng, Wei Xiuran. Discussion on teaching reform of "data structure" in
Software Institute $[\mathrm{J}]$. Education and career, 2013 (27): 140-141.

[3] Li Zhiyi. My opinion on "water class" and "golden class" $[\mathrm{J}]$. Teaching in Chinese universities, 2018 (12): 24-29.

[4] Yan Weimin, Li Dongmei, WU Weimin. Data structure (C language version) (2nd Edition). Beijing: People's Posts and Telecommunications Publishing House. August 2017.

[5] Zhang Shaozhong. Exploration of data structure experiment teaching for engineering education certification [J]. Software, 2020, 41 (10): 310-312.

[6] Wang Lingfen, Li xizuo. Application of online evaluation in practical teaching of data structure $[\mathrm{J}]$. Computer education, 2016 (4): 71-73. 